\title{
Biotecnologia aplicada ao melhoramento genético do cafeeiro
}

\author{
Biotechnology applied to the genetic improvement of coffee plant
}

Tâmara Prado de Morais ${ }^{\mathrm{I}}$ Benjamim de Melo

\section{-REVISÃO BIBLIOGRÁFICA-}

\section{RESUMO}

\begin{abstract}
$O$ melhoramento genético do cafeeiro mediante técnicas convencionais é trabalhoso e demorado. A biotecnologia oferece estratégias alternativas para auxiliar na multiplicação e no desenvolvimento de novas variedades com resistência a estresses bióticos e abióticos, melhor qualidade de bebida e maturação mais uniforme dos frutos. As técnicas de cultura de tecidos têm possibilitado a obtenção de grande número de plantas e a garantia da uniformidade genética do material. $O$ emprego de marcadores moleculares, principalmente através da seleção assistida, facilitou o rápido progresso do melhoramento genético da cultura, assim como a transformação genética, via cultura e fusão de protoplastos, biobalística ou mediada por Agrobacterium sp. Esta revisão objetiva sumarizar o histórico, situação atual e perspectivas da biotecnologia no melhoramento genético do cafeeiro.
\end{abstract}

Palavras-chave: Coffea sp., cultura de tecidos, marcadores moleculares, engenharia genética.

\section{ABSTRACT}

Genetic improvement of coffee through classical breeding is laborious and time consuming. Biotechnology offers alternative strategies to assist multiplication and development of new and improved coffee varieties, including those resistant to biotic and abiotic stresses, with better cup quality, and with uniform fruit maturation. Tissue culture techniques have enabled the production of a large number of plants with genetic uniformity. The use of molecular markers, especially through assisted selection, led to rapid progress of coffee plant breeding, as well as the use of genetic transformation by protoplasts culture and fusion, biobalistics, or Agrobacterium-mediated. This review provides a summary of biotechnology history, current situation and directions applied to the genetic improvement of coffee plant.
Key words: Coffea sp., tissue culture, molecular markers, genetic engineering.

\section{INTRODUÇÃO}

O gênero Coffea engloba cerca de 100 espécies (DAVIS et al., 2006), sendo $\boldsymbol{C}$. arabica e $\boldsymbol{C}$. canephora as mais importantes economicamente. A primeira é uma espécie autógama alopoliplóide (tetraplóide) $\operatorname{com} 2 \mathrm{n}=4 \mathrm{x}=44$ cromossomos, enquanto a segunda é alógama diplóide com $2 n=2 x=22$ cromossomos.

O Brasil é o maior produtor e exportador mundial de café, seguido pelo Vietnã e pela Colômbia (FAO, 2010). No cenário nacional, os maiores estados produtores desse grão são Minas Gerais, Espírito Santo, São Paulo, Bahia, Paraná, Rondônia e Rio de Janeiro, que correspondem a $98 \%$ da produção brasileira. A produção total do país na safra 2010 fechou em 48,09 milhões de sacas de 60 quilos de café beneficiado, o que representou um acréscimo de cerca de $22 \%$ em relação à safra anterior (CONAB, 2010).

Este incremento na produção pode ser justificado pelo ano de bienalidade positiva, aliado às condições climáticas favoráveis no período da floração, e pelas pesquisas com melhoramento genético, que permitiram a utilização de cultivares altamente produtivas e adaptadas às mais distintas condições edafoclimáticas das diversas regiões produtoras do país (EIRA et al., 2001).

Instituto de Ciências Agrárias, Universidade Federal de Uberlândia (UFU), Av. Amazonas, s/n, 38400-902, Uberlândia, MG, Brasil. E-mail: benjamim@umuarama.ufu.br. Autor para correspondência. 
Apesar de as técnicas convencionais de melhoramento apresentarem resultados promissores na cultura do café, no que se refere ao aumento de produtividade e obtenção de novas cultivares resistentes a diversos fatores bióticos e abióticos, demandam de 7 a 8 ciclos de autofecundação para estabilizar o genótipo pela fixação de genes em homozigose. Além de ser um processo demorado e trabalhoso, a eficiência da seleção nas primeiras gerações de autofecundação é muito baixa, devido, principalmente, à ocorrência de alelos dominantes em heterozigose (KALTCHUK-SANTOS \& BODANESEZANETTINI, 2002).

A biotecnologia aplicada ao cafeeiro, através de técnicas de cultura de tecidos vegetais, marcadores moleculares e transformação genética, tem-se revelado importante ferramenta de apoio aos programas de melhoramento, auxiliando na manutenção e conservação de germoplasma utilizado para criação de novas cultivares, identificação e avaliação de novos genótipos, obtenção de novos materiais genéticos em tempo reduzido e, finalmente, multiplicação de novos genótipos. Diante do exposto, esta revisão objetiva sumarizar o histórico, situação atual e perspectivas da biotecnologia aplicada ao melhoramento genético do cafeeiro.

\section{Cultura de tecidos}

A biotecnologia tem aplicações importantes na propagação de cafeeiros, como na multiplicação vegetativa in vitro de híbridos altamente heterozigotos de destacado valor agronômico. As técnicas de cultura de tecidos têm possibilitado a obtenção de grande número de plantas e a garantia da uniformidade genética do material (DUBLIN, 1984). Assim, a clonagem de plantas híbridas promete um fantástico avanço no melhoramento genético do cafeeiro. Plantas de cafeeiro podem ser propagadas por embriogênese somática e microcortes (DUBLIN, 1980), sendo que ambas as metodologias apresentam vantagens e desvantagens (DUBLIN, 1984). A primeira tentativa bem-sucedida de micropropagação de $\boldsymbol{C}$. arabica por gemas axilares foi conduzida por CUSTERS (1980) em meio MS suplementado com $6,64 \mu \mathrm{M}$ da citocinina 6benzilaminopurina (BAP) e meio de subcultivo com $13,29 \mu \mathrm{M}$ de BAP e 1,445 $\mu \mathrm{M}$ de ácido giberélico.

De maneira geral, utiliza-se o meio de cultura básico (MS) suplementado com BAP, que estimula a multibrotação do cafeeiro in vitro (DUBLIN, 1980; CARVALHO et al., 1997). No entanto, novas pesquisas devem ser conduzidas objetivando aprimorar um eficiente protocolo de micropropagação para o cafeeiro, adequado aos diferentes genótipos.
A embriogênese somática em Coffea também é um importante exemplo de multiplicação de plantas-elite in vitro, em larga escala, apresentando grande potencial a ser explorado e capaz de maximizar a propagação do cafeeiro, tanto de cultivares recomendadas para plantio como de híbridos vindos de programas de melhoramento genético (MACIEL et al., 2003).

Os primeiros trabalhos de micropropagação de café via embriogênese somática foram publicados por STARITSKY (1970) para C. canephora e por SÖNDAHL \& SHARP (1977) para $\boldsymbol{C}$. arabica. Atualmente, essa técnica tem sido aplicada com sucesso na maioria dos genótipos de Coffea (SILVA et al., 2005; ALMEIDA et al., 2008). A expectativa é que, em curto prazo, o cafeeiro arábica seja também propagado vegetativamente (TEIXEIRA, 2001).

Diversos tecidos têm sido utilizados para indução de embriões somáticos em café, tais como segmentos de ramos ortotrópicos e plagiotrópicos (STARITSKY, 1970; RAGHURAMULU et al., 1987), tecidos foliares (SÖNDAHL\& SHARP, 1977; QUIROZFIGUEROA et al., 2002), tegumentos do óvulo (LANAUD, 1981) e tecidos somáticos de anteras (ASCANIO \& ARCÍA, 1987) e do perisperma (SREENATH et al., 1995). Até o momento, as folhas têm sido a fonte de explante mais empregada devido a sua acessibilidade durante todo o ano e possibilidade de coleta em diferentes estádios de desenvolvimento.

Um dos principais fatores relacionados à embriogênese somática em café diz respeito à influência do genótipo. A percentagem de formação de calos embriogênicos em $\boldsymbol{C}$. canephora pode variar de 0,0 a 96,9\% e em variedades de $\boldsymbol{C}$. arabica de 0,0 a $10,0 \%$ (BOXTEL\& BERTHOULY, 1996).

O avanço mais recente na propagação clonal do cafeeiro é o uso do sistema de imersão temporária desenvolvido pelo grupo de pesquisa do CIRAD, Montpellier, França (ETIENNE \& BERTHOULY, 2002). Embora a hiperhidricidade seja um problema associado a este sistema, sua ocorrência pode ser eliminada aumentando a frequência de imersões curtas, permitindo até $75 \%$ de conversão de embriões somáticos em plântulas (ALBARRÁN et al., 2005).

O sucesso da micropropagação de plantas depende da taxa de sobrevivência e do desenvolvimento das plantas regeneradas no campo ou em seu habitat (VILLALOBOS \& THORPE, 1991). Alguns aspectos relacionados ao desempenho a campo de mudas micropropagadas de $\boldsymbol{C}$. arabica obtidas via embriogênese somática foram avaliados por GUIMARÃES et al. (1987). Esses autores verificaram que apenas as plântulas com folhas cotiledonares bem 
desenvolvidas sobreviveram à transferência ao solo, sendo os melhores resultados observados quando as plântulas cresceram em meio suplementado com BAP, as quais desenvolveram sistema radicular após o transplantio. $\mathrm{O}$ controle da transpiração durante os primeiros sete dias após o transplantio também influencia decisivamente na sobrevivência das mudas (SANTANA et al., 1996). Esses autores ainda evidenciaram que plântulas com no mínimo 4 pares de folhas produziram populações homogêneas com taxa de sobrevivência de $90 \%$.

Outra técnica de cultura de tecidos bastante aplicada ao melhoramento do cafeeiro é o cultivo de anteras in vitro. Essa ferramenta é empregada como alternativa para acelerar os programas de melhoramento genético na cultura (ANDRADE, 1998), pois permite a obtenção de haplóides em gerações segregantes, o que leva à rápida produção de plantas homozigóticas por intermédio da duplicação do número de cromossomos em uma única etapa, substituindo as gerações de autofecundação (PETERS et al., 1998). Entretanto, a espécie $\boldsymbol{C}$. arabica ainda apresenta poucos progressos quanto à aplicação da cultura de anteras (FIGUEIRA et al., 2008). Assim, é importante identificar as cultivares, a ação e a concentração dos reguladores de crescimento utilizados no meio de cultivo mais responsivos à androgênese.

A primeira tentativa para produção de plantas de cafeeiro haplóides empregando a técnica de cultura de anteras foi realizada em C. arabica (SHARP et al., 1973), sendo possível a regeneração de plantas haplóides e dihaplóides (ASCANIO \& ARCÍA, 1987). A correlação entre os diferentes estádios de desenvolvimento das anteras e o tamanho dos botões florais influencia decisivamente o sucesso dessa técnica (ASCANIO \& ARCÍA, 1987). Em estádios mais avançados da microsporogênese, ocorre um engrossamento da parede celular, sendo esta uma característica do grão de pólen maduro do café, o que prejudica o processo de regeneração (ASCANIO \& ARCÍA, 1994). Dessa forma, o estádio adequado para a androgênese in vitro é o uninucleado, o que corresponde a botões florais entre 4,5 a $6,0 \mathrm{~mm}$ (ASCANIO \& ARCÍA, 1994; SILVA et al., 2004), pois otimiza o processo para a obtenção de plantas haplóides através da cultura de anteras (ANDRADE, 1998).

As anteras devem ser mantidas no escuro para que ocorra o desenvolvimento de calosidade e, após sua formação, para o desenvolvimento do embrião, os calos devem ser mantidos no claro (ASCANIO \& ARCÍA, 1994). Além disso, a ação combinada entre uma auxina e citocinina é necessária para a indução de calos em anteras de cafeeiro (ARAÚJO, 2004).
No entanto, um dos principais problemas enfrentados pelos programas de melhoramento do cafeeiro é a estreita base genética da cultura. Assim, tem-se buscado aumentar sua variabilidade genética, quer seja por métodos tradicionais ou biotecnológicos. Devido barreiras genéticas entre espécies, muitas características desejáveis, como baixo teor de cafeína (SILVAROLLA et al., 2004), não podem ser transferidas para genótipos cultivados por hibridação interespecífica ou intergenérica. Da mesma forma, o cruzamento entre espécies de Paracoffea e Mascarocoffea com Eucoffea é impraticável (MAZZAFERA \& CARVALHO, 1992). Assim, técnicas de cultura e fusão de protoplastos oferecem novas possibilidades para o melhoramento genético do cafeeiro. Os protoplastos podem ser utilizados para produção de híbridos interespecíficos ou intergenéricos e para a introdução de características desejáveis de $\boldsymbol{C}$. canephora, ou qualquer outro diplóide e espécie heterozigota, para C. arabica (NYANGE et al., 1997); também podem ser empregados para transformação genética com DNA exógeno.

O cultivo de protoplastos em cafeeiro tem sido obtido através de folhas (OROZCO \& SCHIEDER, 1984), calos derivados de segmentos foliares (SÖNDAHL et al., 1980), calos embriogênicos (TAHARA et al., 1994), embriões somáticos (SCHOPKE et al., 1987) e culturas de células em suspensão (NYANGE et al., 1997).

O sucesso da cultura de protoplastos (isolamento, cultura e regeneração) depende de uma série de fatores, como o meio de cultivo (KAO \& MICHAYLUK, 1975) e os estádios cronológico e fisiológico das células (SCHOPKE et al., 1987; GRÈZES et al., 1994).

Outra grande aplicação da biotecnologia relacionada ao cafeeiro diz respeito à conservação de material botânico. A cultura in vitro tem permitido a criação de bancos de genótipos em meios de cultura, possibilitando armazenar grande quantidade de material em uma única sala de laboratório. Em contrapartida, essa metodologia exige a transferência constante das plantas (repicagens). Este processo, além de trabalhoso, pode levar a alterações da constituição genética do material (GUERREIRO-FILHO \& COLOMBO, 1998).

A conservação após congelamento em nitrogênio líquido (criopreservação) constitui-se num processo mais confiável e de menor custo. Esta metodologia, estabelecida com sucesso em cafeeiros, garante a conservação por longo tempo sem incorrer em problemas de alteração da constituição genética (DUSSERT et al., 2001). 
Marcadores moleculares

Com relação à identificação e caracterização de variedades, dispõe-se atualmente de tecnologias capazes de revelar diferenças mínimas entre genótipos. Essa tecnologia é denominada de marcadores moleculares do genoma. A partir dessas técnicas, é possível, por exemplo, detectar ambiguidades em coleções de cafeeiros, estabelecer relações de parentesco entre linhagens, cultivares ou espécies diferentes e, sobretudo, identificar com precisão a identidade de uma determinada cultivar em casos de dúvidas (OROZCO-CASTILLO et al., 1994; LASHERMES et al., 1996b).

Dentre as diferentes técnicas de detecção de polimorfismo genético no cafeeiro destacam-se: Polimorfismo de DNA Amplificado ao Acaso - RAPD (OROZCO-CASTILLO et al., 1994; LASHERMES et al., 1996b), Polimorfismo de Comprimento de Fragmentos Amplificados - AFLPe Sequências Simples Repetidas (microssatélites) - SSR (ANTHONY et al., 2002).

Uma das principais aplicações da análise genética é a construção de mapas de ligação. Foram reportados mapas genéticos completos de $\boldsymbol{C}$. canephora (LASHERMES et al., 2001) e de um híbrido interespecífico (C. pseudozanguebarie x C. liberica) (KY et al., 2000). Outros mapas de ligação estão sendo construídos para diferentes espécies de café, incluindo C. arabica. Estes mapas genéticos fornecem informações importantes sobre o genoma do cafeeiro e a organização dos cromossomas. Particularmente, podem ser utilizados para mapear genes importantes (por exemplo, o locus S, que controla a autoincompatibilidade) (LASHERMES et al., 1996a), além de loci que codificam para características quantitativas (QTLs), como compostos bioquímicos que conferem ao café qualidade de bebida (BARRE et al., 1998).

Nesse contexto, merece destaque o Projeto Genoma-Café, desenvolvido por iniciativa do Consórcio Brasileiro de Pesquisa e Desenvolvimento do Café, Embrapa Café, FAPESPe Embrapa Recursos Genéticos e Biotecnologia em parceria com diversas instituições de pesquisa (IAC, UNICAMP, USP, UNESP, IAPAR, UFLA, UFV, Epamig e Incaper). O Projeto resultou em um total de 200.000 ESTs (Expressed Sequence Tags) sequenciados que, após análises de bioinformática, foram agrupados em aproximadamente 35.000 genes distintos (VIEIRA et al., 2006). A partir desse mapeamento, os pesquisadores dispuseram de conhecimentos básicos de genética, fisiologia e bioquímica para desenvolvimento de futuras variedades de cafeeiros com maturação mais uniforme dos frutos, teor controlado de cafeína, resistência a pragas e doenças e tolerância a estresses ambientais, como frio, secas e geadas.
A área de maior impacto dos marcadores moleculares no melhoramento vegetal é através do emprego da seleção assistida para identificação de genótipos superiores em populações segregantes (FEDERIZZI, 1998). Através dessa tecnologia, podese incrementar a eficiência no melhoramento de plantas, pois menor número de progênies por combinação é necessário, bem como menor número de gerações para a estabilização dos genótipos (BARBOSA-NETO, 1998).

Transformação genética

Os primeiros protocolos de transformação em café baseavam-se na integração e expressão de genes em protoplastos (BARTON et al., 1991). Devido aos resultados pouco satisfatórios obtidos através desse método, tentativas para a transformação de café foram feitas usando-se Agrobacterium como vetor (SPIRAL et al., 1993). A partir desse trabalho, vários outros relatos sobre a transformação genética de café têm sido publicados, mediados por Agrobacterium rhizogenes em $\boldsymbol{C}$. arabica e $\boldsymbol{C}$. canephora (SPIRAL \& PÉTIARD, 1993; SUGIYAMA et al., 1995) e mediados por A. tumefaciens (SPIRAL et al., 1999; LEROY et al., 2000).

Recentemente, foram obtidas as primeiras plantas transgênicas de café, expressando o gene de Bacillus thuringiensis (crylAc) que confere resistência a lepidópteros (SPIRAL et al., 1999; LEROY et al., 2000). O bicho-mineiro (Leucoptera coffeella) é responsável pela degradação das folhas e, consequentemente, queda de produção. Através da transformação via $\boldsymbol{A}$. tumefaciens, SPIRAL et al. (1999) obtiveram êxito na transferência do gene crylAc em genótipos de $\boldsymbol{C}$. canephora e de C. arabica. A eficiência da transformação variou dependendo do genótipo testado, sendo os genótipos de cafeeiro arábica menos propícios para a regeneração de embriões. A caracterização molecular evidenciou que $69 \%$ das plantas transformadas continham uma única cópia do T-DNA e que a expressão da proteína CrylAc foi obtida nas folhas de 18 das 23 plântulas testadas (LEROY et al., 2000). Bioensaios conduzidos por estes mesmos autores com duas espécies de bicho-mineiro demonstraram que a proteína CrylAc confere resistência às plantas transgênicas. Nesses experimentos, três diferentes níveis de resistência foram determinados com algumas plantas altamente resistentes, outras pouco sensíveis e algumas plantas totalmente susceptíveis.

Outra metodologia utilizada com sucesso para transformação de café é a biobalística ou bombardeamento de tecidos vegetais. Nesse caso, os 
genes de interesse e os genes marcadores são introduzidos em tecidos vegetais através de uma forte pressão exercida por gás hélio comprimido. Além de uma alta eficiência de transformação, outra vantagem desse método é que o tecido transformado não sofre grandes danos mecânicos. Até o momento, testes realizados com vários tecidos de $\boldsymbol{C}$. arabica, tais como folhas intactas, células em suspensão e calos embriogênicos, foram promissores (BOXTEL et al., 1995).

Protocolos otimizados de transformação via biobalística foram desenvolvidos por ROSILLO et al. (2003) e por RIBAS et al. (2005) para introdução de DNA em células em suspensão de $\boldsymbol{C}$. arabica e em tecidos embriogênicos de $\boldsymbol{C}$. canephora, respectivamente.

A transformação genética de plantas de café já foi obtida por diversos grupos de pesquisa (SPIRAL \& PÉTIARD, 1993; SUGIYAMA et al., 1995; SPIRALet al., 1999; LEROY et al., 2000), mas ainda se trata de um processo difícil, no qual apenas alguns genes foram transferidos com sucesso para genótipos de cafeeiro (SPIRAL et al., 1999).

A transgenia também tem sido empregada para modificar a biossíntese de etileno e de cafeína. Pesquisadores da Universidade do Havaí patentearam a introdução do gene que codifica para as enzimas ácido 1-carboxílico-1-aminociclopropano (ACC) sintase e ACC oxidase em orientação antisenso para reduzir a síntese de etileno e, assim, controlar a maturação dos frutos (DUFOUR et al., 2000; STILES et al., 2004).

\section{CONCLUSÃO}

De maneira geral, as técnicas de biotecnologia vegetal são de grande utilidade no melhoramento genético do cafeeiro e várias delas vêm sendo aplicadas com relativa eficiência em pesquisas realizadas por diferentes instituições. Cabe salientar, no entanto, que a utilização dos produtos gerados pela pesquisa científica, por parte dos diferentes elos da cadeia produtiva do café, está na dependência direta de investimentos regulares no setor e na constante capacitação técnica dos profissionais envolvidos. As técnicas de genética molecular são empregadas no melhoramento do cafeeiro apenas como ferramentas auxiliares aos programas convencionais em andamento no país. Técnicas que envolvem marcadores moleculares de DNA e mapeamento genético do cafeeiro são utilizadas para monitorar os programas de seleção de plantas, o que reduz o tempo demandado para o lançamento de novas cultivares de cafeeiro, além de aumentar grandemente a sua eficiência. Da mesma forma, técnicas de cultivo de grãos de pólen e de anteras reduzem o tempo necessário para a obtenção de novas linhagens de cafeeiros. A produção de transgênicos, com o uso das técnicas de transformação genética, também se revela interessante para o melhoramento genético do cafeeiro, pois pode gerar novas cultivares diretamente, ou genótipos para serem utilizados em um programa de melhoramento convencional. Por tudo isso, espera-se que dentro de poucos anos o melhoramento genético do cafeeiro consiga avançar com maior rapidez.

\section{REFERÊNCIAS}

ALBARRÁN, J. et al. Cycle characteristics in a temporary immersion bioreactor affect regeneration, morphology, water and mineral status of coffee (Coffea arabica) somatic embryos. Plant Cell, Tissue and Organ Culture, v.81, n.1, p.27-36, 2005. Disponível em: <http://dx.doi.org/10.1007/s11240-0042618-8>. Acesso em: 10 mar. 2011. doi: 10.1007/s11240004-2618-8.

ALMEIDA, J.A.S. et al. Embriogênese somática em genótipos de Coffea arabica L. Coffee Science, v.3, n.2, p.143-151, 2008. Disponível em: <http://www.coffeescience.ufla.br/ojs/ index.php/Coffeescience/article/viewFile/85/173>. Acesso em: 10 mar. 2011

ANDRADE, L.M.C.O. Otimização de técnicas de cultura de tecidos para o cafeeiro (Coffea arabica L.). 1998. $84 \mathrm{f}$. Dissertação (Mestrado em Genética e Melhoramento de Plantas) - Universidade Federal de Lavras, MG.

ANTHONY, F. et al. The origin of cultivated Coffea arabica L. varieties revealed by AFLP and SSR markers. Theoretical and Applied Genetics, v.104, n.5, p.894-900, 2002. Disponível em: <http://horizon.documentation.ird.fr/exl-doc/ pleins_textes/pleins_textes_7/divers2/010029197.pdf>. Acesso em: 10 mar. 2011. doi: 10.1007/s00122-001-0798-8.

ARAÚJO, J.S. Calogênese em anteras de cafeeiro Coffea arabica L. 2004. 41f. Tese (Doutorado em Fitotecnia) Universidade Federal de Lavras, MG.

ASCANIO, E.C.E.; ARCÍA, M.A.M. Haploids from anther culture in Coffea arabica L. In: INTERNATIONAL CONGRESS OF PLANT TISSUE CULTURE, 1987, Bogotá, Colombia. Abstracts... Bogotá: IAPTC, 1987. p.68.

ASCANIO, E.C.E.; ARCÍA, M.A.M. Efecto de un shock termico sobre la androgénesis en Coffea arabica L. var. Garnica. Agronomía Tropical, v.44, n.2, p.165-177, 1994. Disponível em: <http://avepagro.org.ve/agrotrop/v44_2/v442a010.html>. Acesso em: 10 mar. 2011.

BARBOSA-NETO, J.F. Seleção assistida por marcadores moleculares. In: MILACH, S.C.K. Marcadores moleculares em plantas. Porto Alegre: UFRGS, 1998. p.75-80.

BARRE, P. et al. Inheritance of caffeine and heteroside contents in an interspecific cross between a cultivated coffee species Coffea liberica and a wild species caffeine free $\boldsymbol{C}$. pseudozangebariae. Theoretical and Applied Genetics, 
v.96, n.2, p.306-311, 1998. Disponível em: <http://dx.doi.org/ 10.1007/s001220050741>. Acesso em: 10 mar. 2011. doi: $10.1007 / \mathrm{s} 001220050741$.

BARTON, C.R. et al. Stable transformation of foreign DNA into C. arabica plants, Paris, 1991. In: COLLOQUE SCIENTIFIQUE INTERNATIONAL SUR LE CAFÉ, 14., 1991, Paris. Resumos Expandidos... Paris: Association Scientifique Internacionale du Café (ASIC), 1991. p.460-464

BOXTEL, J.V. et al. Transient expression of B-glucuronidase following biolistic delivery of foreign DNA into coffee tissues. Plant Cell Reports, v.14, n.12, p.748-752, 1995. Disponível em: <http://dx.doi.org/10.1007/BF00232915>. Acesso em: 10 mar. 2011. doi: 10.1007/BF00232915.

BOXTEL, J.V.; BERTHOULY, M. High frequency somatic embryogenesis from coffee leaves. Plant Cell, Tissue and Organ Culture, v.44, n.1, p.7-17, 1996. Disponível em: <http://dx.doi.org/10.1007/BF00045907>. Acesso em: 10 mar. 2011. doi: 10.1007/BF00045907.

CARVALHO, G.R. et al. Efeito do triadimenol e benzilaminopurina no desenvolvimento de brotos in vitro do cafeeiro cv. Catuaí. Revista Unimar, v.19, n.3, p.767-775, 1997. Disponível em: <http://periodicos.uem.br/ojs/index.php/ RevUNIMAR/article/view/4584/3107>. Acesso em: 10 mar. 2011.

CONAB - COMPANHIA NACIONAL DE ABASTECIMENTO. Acompanhamento da safra brasileira: café. Safra 2010 , quarta estimativa, dezembro/2010, 20p. Disponível em: <http:/ /www.conab.gov.br/OlalaCMS/uploads/arquivos/ 10_12_14_11_47_58_boletim__cafe__dezembro_2010..pdf >. Acesso em: 11 mar. 2011.

CUSTERS, J.B.M. Clonal propagation of Coffea arabica L. by nodal culture, Montpellier, 1980. In: COLLOQUE SCIENTIFIQUE INTERNATIONAL SUR LE CAFÉ, 9., 1980, Montpellier. Resumos expandidos... Paris: Association Scientifique Internacionale du Café (ASIC), 1980. p.588-596.

DAVIS, A.P. et al. An annotated taxonomic conspectus of the genus Coffea (Rubiaceae). Botanical Journal of the Linnean Society, v.152, p.465-512, 2006. Disponível em: <http:// dx.doi.org/10.1111/j.1095-8339.2006.00584.x>. Acesso em: 11 mar. 2011. doi: 10.1111/j.1095-8339.2006.00584.x.

DUBLIN, P. Multiplication vegetative in vitro de L'arabusta. Café, Cacao, Thé, v.24, n.2, p.281-290, 1980. Disponível em: <http://horizon.documentation.ird.fr/exl-doc/pleins_textes/ pleins_textes_5/b_fdi_02-03/03734.pdf >. Acesso em: 11 mar. 2011.

DUBLIN, P. Tequiniques de reproduction vegétative in vitro et amelioration genétique chez les cafélers cultives. Café, Cacao, Thé, v.28, p.231-244, 1984.

DUFOUR, M. et al. Coffee (Coffea sp.) genetic transformation for insect resistance. In: SERA, T. et al. Coffee biotechnology and quality. Netherlands: Kluwer, 2000. p.209-217.

DUSSERT, S. et al. Tolerance of coffee (Coffea spp.) seeds to ultra-low temperature exposure in relation to calorimetric properties of tissue water, lipid composition and cooling procedure. Physiologia Plantarum, v.112, p.495-504, 2001.
Disponível em: <http://dx.doi.org/10.1034/j.13993054.2001.1120406.x>. Acesso em: 11 mar. 2011. doi: 10.1034/j.1399-3054.2001.1120406.x.

EIRA, M.T.S. et al. Aumento da variabilidade genética de café no Brasil. Coffee Break. Brasília: EMBRAPA Café, 2001. Disponível em: <http://www.coffeebreak.com.br/ ocafezal.asp?SE=8\&ID=309>. [Online]. Acesso em: 4 mar. 2010 .

ETIENNE, H.; BERTHOULY, M. Temporary immersion systems in plant micropropagation. Plant Cell, Tissue and Organ Culture, v.69, p.215-231, 2002. Disponível em: <http://dx.doi.org/10.1023/A:1015668610465>. Acesso em: 11 mar. 2011. doi: 10.1023/A:1015668610465.

FAO - FOOD AND AGRICULTURE ORGANIZATION. FaoStat. Disponível em: <http://faostat.fao.org/site/291/ default.aspx>. Acesso em: 4 mar. 2010.

FEDERIZZI, L.C. Estrutura de um programa de melhoramento de plantas e possíveis aplicações de marcadores moleculares: visão do melhorista. In: MILACH, S.C.K. Marcadores moleculares em plantas. Porto Alegre: UFRGS, 1998. p.3-15.

FIGUEIRA, E.R. et al. Influência do 2,4-D, nitrato de prata e ácido acetilsalicílico no cultivo in vitro de anteras de cafeeiro. Científica, v.36, n.1, p.27-33, 2008.

GRÈZES, J. et al. Factors influencing protoplast isolation from Coffea arabica cells. Plant Cell, Tissue and Organ Culture, v.36, p.91-97, 1994. Disponível em: <http:// dx.doi.org/10.1007/BF00048319>. Acesso em: 11 mar. 2011. doi: $10.1007 / \mathrm{BF} 00048319$.

GUERREIRO-FILHO, O.; COLOMBO, C.A. Biotecnologia na cafeicultura. Coffee Break. Informativo Garcafé, 1998. Disponível em: 〈http://www.coffeebreak.com.br/ocafezal.asp?SE=8\&ID=58>. [Online]. Acesso em: 4 mar. 2010.

GUIMARÃES, M.L. et al. Problems of soil adaptation in plantlets of Coffea arabica L. obtained via somatic embryogenesis. Acta Horticulturae, v.212, p.315-321, 1987. Disponível em: <http:/ /www.actahort.org/books/212/212_47.htm>. Acesso em: 11 mar. 2011.

KALTCHUK-SANTOS, E.; BODANESE-ZANETTINI, M.H. Androgênese: uma rota alternativa no desenvolvimento do pólen. Ciência Rural, v.32, n.1, p.165-173, 2002. Disponível em: <http://www.scielo.br/scielo.php?script=sci_arttext\&pid=S0103$84782002000100028 \& \operatorname{lng}=$ en $\& n r m=i s o>$. Acesso em: $11 \mathrm{mar}$. 2011. doi: $10.1590 / \mathrm{S} 0103-84782002000100028$.

KAO, K.N.; MICHAYLUK, R. Nutritional requirements for growth of Vicia hajastana cells and protoplasts at a very low population density in liquid media. Planta, v.126, p.105-110, 1975. Disponível em: 〈http://dx.doi.org/10.1007/BF00380613〉. Acesso em: 11 mar. 2011. doi: 10.1007/BF00380613.

KY, C.L. et al. Interspecific genetic linkage map, segregation distortion and genetic conversion in coffee (Coffea sp.). Theoretical and Applied Genetics, v.101, p.669-676, 2000. Disponível em: 〈http://dx.doi.org/10.1007/s001220051529>. Acesso em: 11 mar. 2011. doi: 10.1007/s001220051529.

LANAUD, C. Production of Coffea canephora plantlets by somatic embryogenesis obtained by in vitro culture of ovules. Café, Cacao, Thé, v.25, p.231-236, 1981. 
LASHERMES, P. et al. Inheritance and genetic mapping of self-incompatibility in Coffea canephora Pierre. Theoretical and Applied Genetics, v.93, n.3, p.458-462, 1996a. Disponível em: <http://dx.doi.org/10.1007/BF00223190>. Acesso em: 11 mar. 2011. doi: 10.1007/BF00223190.

LASHERMES, P. et al. Genetic diversity for RAPD markers between cultivated and wild accessions of Coffea arabica. Euphytica, v.87, n.1, p.59-64, 1996b. Disponível em: <http:/ /dx.doi.org/10.1007/BF00022965>. Acesso em: 11 mar. 2011. doi: 10.1007/BF00022965.

LASHERMES, P. et al. Genetic linkage map of Coffea canephora: effect of segregation distortion and analysis of recombination rate in male and female meioses. Genome, v.44, n.4, p.589-595, 2001. Disponível em: <http://article.pubs.nrc-cnrc.gc.ca/RPAS/ rpv?hm=HInit\&journal=gen\&volume $=44 \&$ calyLang=eng\&afpf $=\mathrm{g} 01$ 041.pdf>. Acesso em: 11 mar. 2011. doi: 10.1139/gen-44-4-589.

LEROY, T. et al. Genetically modified coffee plants expressing the Bacillus thuringiensis crylAc gene for resistance to leaf miner. Plant Cell Reports, v.19, p.382-389, 2000.

MACIEL, A.L.R. et al. Embriogênese somática indireta em explantes foliares de Coffea arabica L. cv. Obatã. Ciência e Agrotecnologia, v.27, n.1, p.107-116, 2003.

MAZZAFERA, P.; CARVALHO, A. Breeding for low caffeine content of coffee (Coffea L.) by interspecific hybridization. Euphytica, v.59, n.1, p.55-60, 1992. Disponível em: <http:/ /dx.doi.org/10.1007/BF00025361>. Acesso em: 11 mar. 2011. doi: $10.1007 / \mathrm{BF} 00025361$.

NYANGE, N.E. et al. Plant regeneration from suspension culture protoplats established from hypocotyl-derived callus of two Coffea arabica genotypes, Nairobi, 1997. In: COLLOQUE SCIENTIFIQUE INTERNATIONAL SUR LE CAFÉ, 17., 1997, Nairobi. Resumos expandidos... Paris: Association Scientifique Internacionale du Café (ASIC), 1997. p.779-782.

OROZCO, F.J.; SCHIEDER, O. Isolation of mesophyll protoplasts of the genus Coffea. Turrialba, v.34, p.534-536, 1984.

OROZCO-CASTILLO, C. et al. Detection of genetic diversity and selective gene introgression in coffee using RAPD markers. Theoretical and Applied Genetics, v.87, n.8, p.934-940, 1994. Disponível em: 〈http://dx.doi.org/10.1007/BF00225787〉. Acesso em: 11 mar. 2011. doi: 10.1007/BF00225787.

PETERS, J.A. et al. Produção de haplóides e duplohaplóides. In: TORRES, A.C. et al. Cultura de tecidos e transformação genética de plantas. Brasília: EMBRAPA-SPI/EMBRAPACNPH, 1998. V.1, p.569-612.

QUIROZ-FIGUEROA, F.R. et al. Histological studies on the developmental stages and differentiation of two different somatic embryogenesis systems of Coffea arabica. Plant Cell Reports, v.20, n.12, p.1141-1149, 2002. Disponível em: <http://dx.doi.org/10.1007/s00299-002-0464-x>. Acesso em: 11 mar. 2011. doi: 10.1007/s00299-002-0464-x.

RAGHURAMULU, Y. et al. In vitro regeneration of coffee plantlets in India. Journal of Coffee Research, v.17, p.5764; 1987.

RIBAS, A.F. et al. Genetic transformation of Coffea canephora by particle bombardment. Biologia Plantarum, v.49, n.4, p.493-497, 2005. Disponível em: <http://dx.doi.org/10.1007/ s10535-005-0038-1>. Acesso em: 11 mar. 2011. doi: 10.1007/ s10535-005-0038-1.

ROSILLO, A.G. et al. Optimised DNA delivery into Coffea arabica suspension culture cells by particle bombardment. Plant Cell, Tissue and Organ Culture, v.74, n.1, p.45-49, 2003. Disponível em: 〈http://dx.doi.org/10.1023/A:1023314128543〉. Acesso em: 11 mar. 2011. doi: 10.1023/A:1023314128543.

SANTANA, N. et al. Adaptación de vitroplantas de embriones somáticos de cafeto (C. arabica L.) variedad Catimor (9722). Cultivos Tropicales, v.17, n.2, p.83-85, 1996.

SCHOPKE, C. et al. Somatic embryogenesis and regeneration of plantlets in protoplast cultures from somatic embryos of coffee (Coffea canephora P. ex Fr.). Plant Cell, Tissue and Organ Culture, v.8, n.3, p.243-248, 1987. Disponível em: <http://dx.doi.org/10.1007/BF00040951>. Acesso em: 11 mar. 2011. doi: 10.1007/BF00040951.

SHARP, W.R. et al. Production of Coffea arabica callus of three ploidy levels and subsequent morphogenesis. Phyton, v.31, n.2, p.67-74, 1973.

SILVA, A.S. et al. Relação entre os estádios de desenvolvimento dos micrósporos e as características morfológicas do botão floral para o cafeeiro (Coffea arabica L.). Bioscience Journal, v.20, n.1, p.41-45, 2004. Disponível em: <http://www.seer.ufu.br/ index.php/biosciencejournal/article/viewFile/6488/4222>. Acesso em: 11 mar. 2011.

SILVA, R.F. et al. Primary and secondary somatic embryogenesis in leaf sections and cell suspensions of Coffea arabica cv. Catimor. Interciencia, v.30, p.694-698, 2005.

SILVAROLLA, M.B. et al. A naturally decaffeinated arabica coffee. Nature, v.429, p.826, 2004. Disponível em: <http:// www.nature.com/nature/journal/v429/n6994/abs/ 429826a.html>. Acesso em: 11 mar. 2011. doi: 10.1038/ 429826a.

SÖNDAHL, M.R.; SHARP, W.R. High frequency induction of somatic embryos in cultured leaf explants of Coffea arabica $\mathrm{L}$. Zeitschrift fur Pflanzenphysiologie, v.81, n.5, p.395-408, 1977.

SÖNDAHL, M.R. et al. Protoplast liberation, cell wall reconstitution, and callus proliferation in Coffea arabica L. callus tissues. Turrialba, v.30, n.2, p.161-165, 1980.

SPIRAL, J.; PÉTIARD, V. Développement d'une méthode de transformation appliqueé a différentes espèces de caféir et régénération de plantules transgéniques, Montpellier, 1993. In: COLLOQUE SCIENTIFIQUE INTERNATIONAL SUR LE CAFÉ, 15., 1993, Montpellier. Resumos expandidos... Paris: Association Scientifique Internacionale du Café (ASIC), 1993. p.115-122.

SPIRAL, J. et al. Obtention de plantules de Coffea canephora Pierre (Robusta) transformées par Agrobacterium rhizogenes. Comptes Rendus de l'Académie des Sciences, v.316, n.1, p.1-6, 1993.

SPIRAL, J. et al. Transgenic coffee (Coffea species). In: BAJAJ, Y.P.S. Biotechnology in agriculture and forestry. 
Transgenic trees. Berlin: Heidelberg: Springer Verlag, 1999. V.44, p.55-76.

SREENATH, H.L. et al. Somatic embryogenesis from integument (perisperm) cultures of coffee. Plant Cell Reports, v.14, n.10, p.670-673, 1995. Disponível em: <http://dx.doi.org/ 10.1007/BF00232736>. Acesso em: 11 mar. 2011. doi: $10.1007 / \mathrm{BF} 00232736$

STARITSKY, G. Embryoid formation in callus cultures of coffee. Acta Botanica, v.19, n.4, p.509-514, 1970.

STILES, J.I. et al. Purified proteins, recombinant DNA sequences and processes for controlling the ripening of coffee plant. US Patent 6.727.406 B2, 2004.

SUGIYAMA, M. et al. Transformation of Coffea with Agrobacterium rhizogenes, Kioto, 1995. In: COLLOQUE SCIENTIFIQUE INTERNATIONAL SUR LE CAFÉ, 16., 1995,

Kioto. Resumos expandidos... Paris: Association Scientifique Internacionale du Café (ASIC), 1995. p.853-859.
TAHARA, M. et al. Formation of somatic embryos from protoplasts of Coffea arabica L. HortScience, v.29, p.172174,1994

TEIXEIRA, J.B. Limitações ao processo de cultivo in vitro de espécies lenhosas, Goiânia, 2001. In: ENCONTRO LATINOAMERICANO DE BIOTECNOLOGIA VEGETAL, 4., 2001, Goiânia. Palestra... Goiânia: REDBIO, 2001. p.110-113.

VIEIRA, L.G.E. et al. Brazilian coffee genome project: an EST-based genomic resource. Brazilian Journal of Plant Physiology, v.18, n.1, p.95-108, 2006. Disponível em: <http:/ $/$ www.scielo.br/scielo.php? script $=$ sci_arttext\&pid $=$ S 1677 $04202006000100008 \& \operatorname{lng}=e n \& n r m=i s o>$. Acesso em: $11 \mathrm{mar}$. 2011. doi: $10.1590 / \mathrm{S} 1677-04202006000100008$

VILLALOBOS, A.V.M.; THORPE, T.A. Micropropagación: conceptos, metodologíá y resultados. In: ROCA, W.M.; MROGINSKI, L.A. Cultivo de tejidos en la agricultura: fundamentos y aplicaciones. Colombia: Centro Internacional de Agricultura Tropica. 1991. p.127-141. 